
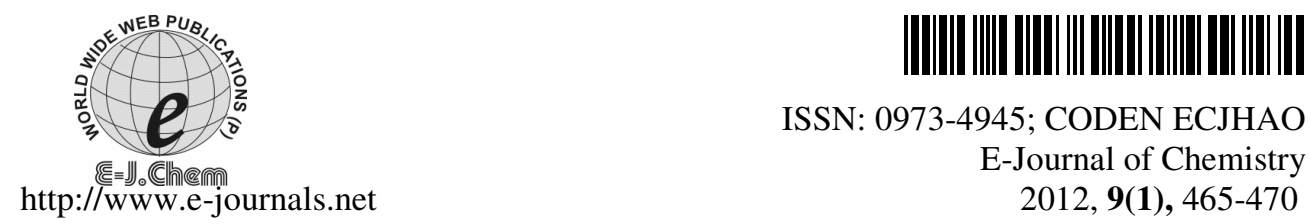

ISSN: 0973-4945; CODEN ECJHAO

E-Journal of Chemistry 2012, 9(1), 465-470

\title{
Synthesis and Characterization of Azo Dye Para Red and New Derivatives
}

\author{
L ABD-ALREDHA R.AL-RUBAIE* and R. JAMEEL MHESSN, \\ Department of Pharmaceutical Chemistry, \\ Pharmacy College, Basrah University, Iraq \\ leaqaa2000@yahoo.com
}

Received 5 February 2011; Revised 13 May 2011; Accepted 5 June 2011

\begin{abstract}
Azo dyes para red was synthesized. The products were characterized by FTIR and UV-Visible spectrophotometers. The antibacterial activities of the compounds were studied using gram positive and gram negative microorganism.
\end{abstract}

Keywords: Azo dye, Para red derivatives, Diazonium salts reaction, Synthesis

\section{Introduction}

Azo dyes contain at least one nitrogen-nitrogen double bond $(\mathrm{N}=\mathrm{N})$; however many different structures are possible ${ }^{1}$. Monoazo dyes have only one $\mathrm{N}=\mathrm{N}$ double bond, while diazo and triazo dyes contain two and three $\mathrm{N}=\mathrm{N}$ double bonds, respectively. The azo groups are generally connected to benzene and naphthalene rings, but can also be attached to aromatic heterocycles or enolizable aliphatic groups. These side groups are necessary for imparting the color of the dye, with many different shades and intensities being possible. A common example of an azo dye is shown in Figure 1. When describing a dye molecule, nucleophiles are referred to as auxochromes, while the aromatic groups are called chromophores. Together, the dye molecule is often described as a chromogen. Synthesis of most azo dyes involves diazotization of a primary aromatic amine, followed by coupling with one or more nucleophiles. Amino- and hydroxy- groups are commonly used coupling components ${ }^{1}$. Because of the diversity of dye components available for synthesis, a large number of structurally different azo dyes exist and are used in industry ${ }^{2}$. World wide production of organic dyes is currently estimated at nearly 450,000 tons, with 50,000 tons being lost in effluents during application and manufacture ${ }^{3}$. 


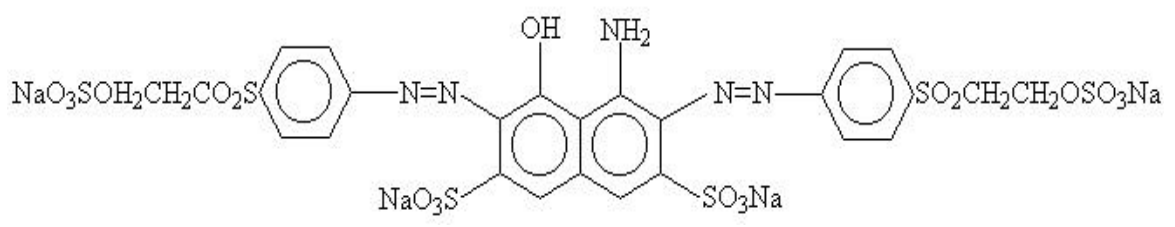

Figure 1. Example of an azo dye structure

Azo dyes acquired wide interest in application to biological system and indicator in complexometric titration of analytical chemistry. Azo dyes are the most important group of synthetic colorants. They are generally considered as xenobiotic compounds that are very recalcitrant against biodegradative processes. Aromatic azo compounds especially are used as acid-base indicators, also used in biological strains and commercial colorants for clothing, plastics, cosmetics and food beverages. Color changes are caused by change in extent of delocalization of electrons. More delocalization shifts the absorption max to longer wave lengths and makes the light absorbed redder, while less delocalization shifts the absorption max to shorter wavelengths.

In pharmaceutical, azo linkage was used to protect drug from undesirable reaction, such as prontosil was found to protect against, and cure streptococcal infections in mice. Interestingly prontosil was inactive on bacterial cultures. Prontosil is totally in active in vitro but possesses excellent activity in vivo ${ }^{4}$. Due to the highly variable nature of biological treatment systems and especially textile effluents, there are a number of factors that may affect the biodegradation rate of azo dyes. Throughout the literature, researchers have discussed various problems associated with dye biodegradation that may or may not be anticipated or remedied. Non-dye related parameters such as temperature, $\mathrm{pH}$, type and source of reduction equivalents, bacteria consortium, and cell permeability can all affect the biodegradation of azo dyes and textile effluents. Dye related parameters such as class and type of azo dye (i.e. reactive-monoazo), reduction metabolites, dye concentration, dye side-groups, and organic dye additives could also affect the biodegradability of azo dye wastewaters.

The azo dye structure can play a significant role in the dye biodegradation rate. Depending on the number and placement of the azo linkages, some dyes will biodegrade more rapidly than others. In general, the more azo linkages that must be broken will cause the reduction rate to be slower. While there are not a large number of studies that specifically address this factor, Brown and Laboureur ${ }^{5}$ observed that two poly-azo dyes showed only moderate to variable biodegradation as compared to four monoazo and six diazo dyes. The authors indicate that poly-azo dyes are less likely to degraded than mono- or diazo dye types ${ }^{5}$.

The azo dye sulfonamides antibacterial drugs were the first effective chemotherapeutic agents that could be used systemically for the cure of bacterial infection in humans. A series of azo dyes containing the sulfonamide functional group were synthesized as potential antimicrobial agents, sulfonamide was classified into three different types; antibacterials that are aniline-substituted sulfonamides, prodrug that react to generate active sulfanilamides and nonanilin sulfonamides. There are also other commonly used drugs that are azo dyes sulfonamides or sulfanilamides (the diuretic furosemide,the diuretic chlorthlidone and the oral hypoglycemic drug tolbutamide). Today, there are a few sulfonamides and especially sulfonamide-trimethoprim combination that are used extensively for opportunistic infection in the patients with AIDS $^{6}$. 


\section{Experimental}

Preparation of azo dye para red (dye I)

Preparation of diazonium salt

Solution of $1 \mathrm{~mL}$ of concentrated sulfuric acid in $10 \mathrm{~mL}$ of distilled water was added in a round botton flask. While stirring, $1 \mathrm{~g}$ (7 mmol) of $p$-nitroaniline was added with stirring in ice bath. Then solution of $0.5 \mathrm{~g}(7 \mathrm{mmol})$ of sodium nitrate in $2 \mathrm{~mL}$ of distilled water was added slowly.

\section{Synthesis of para red}

Solution of $1 \mathrm{~g}$ (7 mmol) of 2-naphthol in $10 \mathrm{~mL}$ of $2.5 \mathrm{M}$ sodium hydroxide was added into the flask with the diazonium salt in an ice bath, with vigorously stirring for a few minutes. The mixture was acidified with $1 \mathrm{M}$ sulfuric acid. The product was dried under vacuum-oven at $50{ }^{\circ} \mathrm{C}$ for $2 \mathrm{~h}$. The melting point of product was estimated at $248-252{ }^{\circ} \mathrm{C}$, the red product was characterized by FTIR and UV spectrophotometer as shows in Figures 2 and 5 respectively.

\section{Preparation of methylsulfonyl para red (dye II)}

Methane sulfonyl chloride $(0.023 \mathrm{~mL})$ was added drop wise over 15 minutes in an ice cooled solution of para red $(0.461 \mathrm{mmol})$ and $5 \mathrm{~mL}$ tripropylamine. The resulting red suspension was stirred at $0{ }^{\circ} \mathrm{C}$ for 20 minutes, extracted with chloroform, the dye II was dried under vacuum-oven for $24 \mathrm{~h}$ at $50{ }^{\circ} \mathrm{C}$, the melting point was $267^{\circ} \mathrm{C}$, the product was characterized by FTIR and UV spectrophotometers, as shown in Figures 3 and 5 respectively.

\section{Preparation of dye III}

A solution of $1 \mathrm{~g}$ ( $7 \mathrm{mmol})$ of 4-amino-3-hydroxynaphthalene -1-sulphonic acid in $10 \mathrm{~mL}$ of $2.5 \mathrm{M}$ sodium hydroxide was added into the flask with the diazonium salt in an ice bath (form swelling) with vigorous stirring for 30 minutes. The mixture was acidified with $1 \mathrm{M}$ sulfuric acid, the product was filtered and washed with distilled water. The dried product was decomposed at $280{ }^{\circ} \mathrm{C}$. The product was investigated by IR and UV spectrophotometer, as shown in Figures 4 and 5 respectively.

\section{Results and Discussion}

The synthesis of an azo dye requires two organic compounds- a diazonium salt and a coupling component. The general synthesis of azo dyes is shown below:

The diazonium salt reacts as an electrophile with an electron-rich coupling component, like a $\beta$-naphthol and naphthaline derivative through an electrophilic aromatic substitution mechanism. The hydroxyl group (such as $\beta$-naphthol) direct the aryl diazonium ion to the para site unless that position is occupied, in which case the ion attaches ortho ${ }^{7}$.

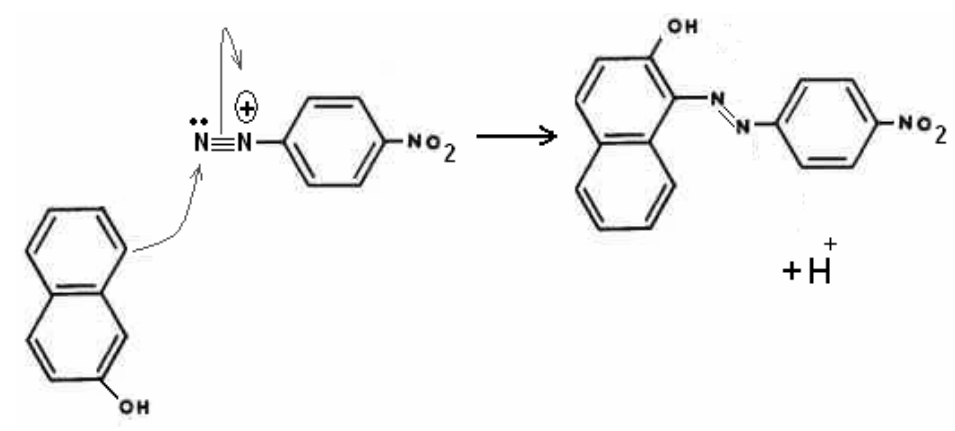


The prepared products as azo dye were characterized by various available techniques. The infrared spectroscopy is one of the efficient techniques used in the characterization of organic compounds. IR spectrophotometers as FTIR which was used in the present study to confirm the presence of functional groups as following, distinguish stretching vibration band of azo group $(\mathrm{N}=\mathrm{N})$ at $1500.52-1521.73 \mathrm{~cm}^{-1}$ as shown ${ }^{8}$ in Figures 2 to 4.The stretching vibration appear at $2962.46 \mathrm{~cm}^{-1}$ and $2927.74 \mathrm{~cm}^{-1}$ position was related to methyl group of methylsulfonyl group $\left(\mathrm{CH}_{3} \mathrm{SO}_{2}\right)$ as shown in Figure 3. The compound III differ from the compound I and II by replace $\beta$-naphthol by 4-amino-3-hydroxy-naphthalene-1-sulphonic acid. The asymmetry stretching vibration of $\mathrm{S}-\mathrm{O}\left(\mathrm{SO}_{3}-\mathrm{H}\right)$ group appearance at $1172.6 \mathrm{~cm}^{-1}$ position, while symmetry at $1045.35 \mathrm{~cm}^{-1}$ position.Other peaks of the principle bands are shown in Table 1.

Table 1. Major stretching vibration of absorption bands by FTIR spectroscopy

\begin{tabular}{|c|c|c|c|c|c|c|}
\hline Compounds & $v_{\mathrm{N}=\mathrm{N}}$ str. & $v_{\mathrm{NO}_{2}}$ str. & $\begin{array}{l}v_{\mathrm{O}-\mathrm{H}} \text { str. } \\
\text { (Phenolic) }\end{array}$ & $v_{\mathrm{C}-\mathrm{H} \text { str. }}$ & $v_{\mathrm{SO}_{2}}$ str. & $v_{\mathrm{SO}_{3}}$ str. \\
\hline Dye I & 1504.37 & 1328.86 & 3390 & - & - & $\begin{array}{l}1172.6 \text { asy. } \\
1045.35 \text { sym }\end{array}$ \\
\hline Dye II & 1500.52 & 1330.79 & - & $\begin{array}{l}2962.46 \text { asy. } \\
2927.7 \text { sym }\end{array}$ & 1400 & - \\
\hline Dye III & 1521.73 & 1344.29 & 3450 & - & - & - \\
\hline
\end{tabular}
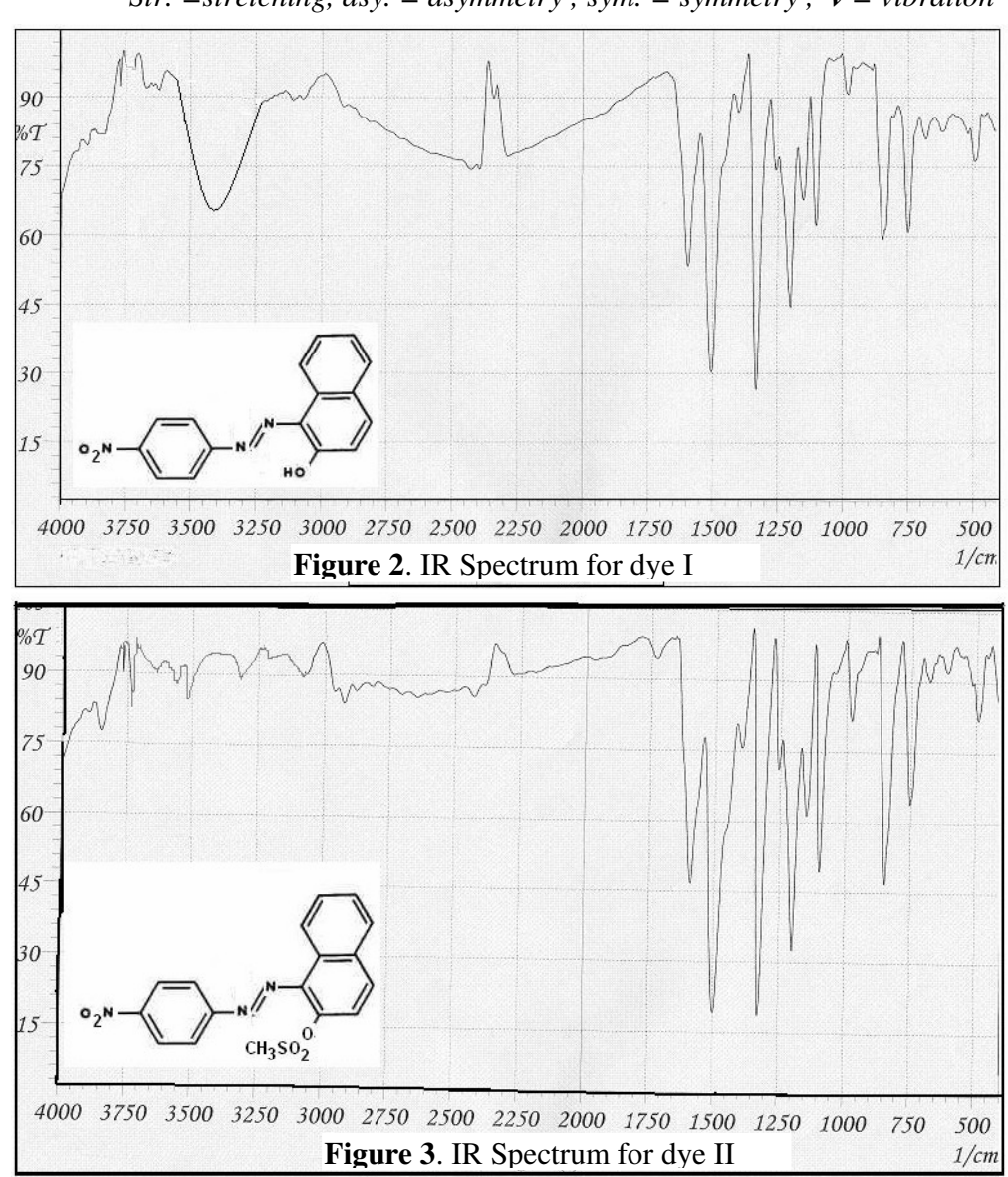


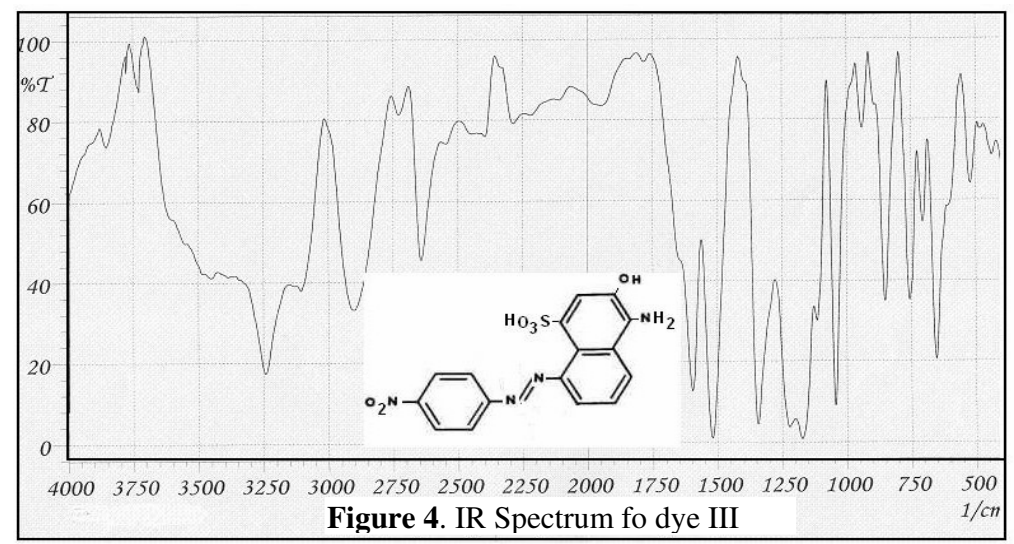

The UV-Visible spectrophotometer study was showed the same position of transition dye I and II in curve, as shown in Figure 5, but differ in intensity. Both dye I and II have a structure with distinct electron donor and acceptor groups, the so called "Push-Pull" electron structure. The maximum absorption band is a broad peak that probably embraces the absorption ascribed either to $\mathrm{n} \rightarrow \pi$ or $\mathrm{n} \rightarrow \pi^{*}$ electron transitions, as shown in Table 2 .

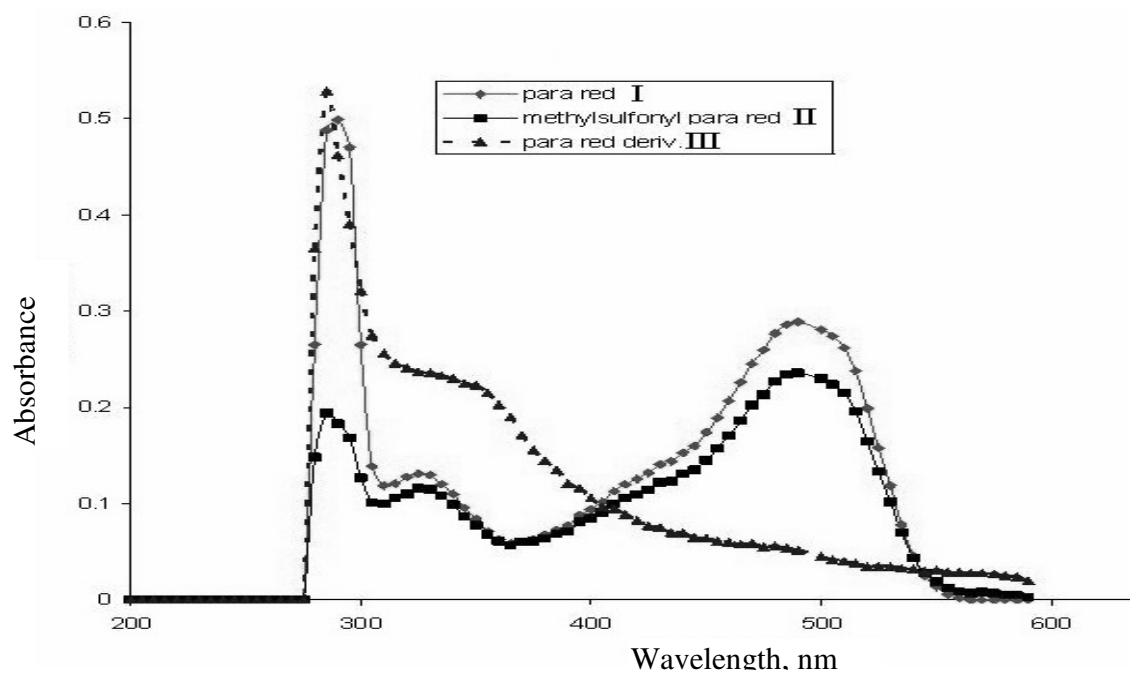

Figure 5. UV-Visible curves of compounds (I, II and III)

Table 2. Types of UV-Visible transition

\begin{tabular}{lcl}
\hline Compounds & Type of transition & Wave length, $\mathrm{nm}$ \\
\hline Dye I & $\pi \rightarrow \pi^{*}$ & 285 sharp \\
& $\mathrm{n} \rightarrow \pi^{*}$ & 325 shoulder \\
& $\pi \rightarrow \pi^{*}$ & 490 tautomerism \\
Dye II & $\pi \rightarrow \pi^{*}$ & 290 weak \\
& $\mathrm{n} \rightarrow \pi^{*}$ & 325 shoulder \\
& $\pi \rightarrow \pi^{*}$ & 490 tautomerism \\
Dye III & $\pi \rightarrow \pi^{*}$ & 330 sharp \\
& $\mathrm{n} \rightarrow \pi^{*}$ & 490 shoulder \\
\hline
\end{tabular}


The broader transition may be due to hyperconjugation system of the molecule ${ }^{8}$.

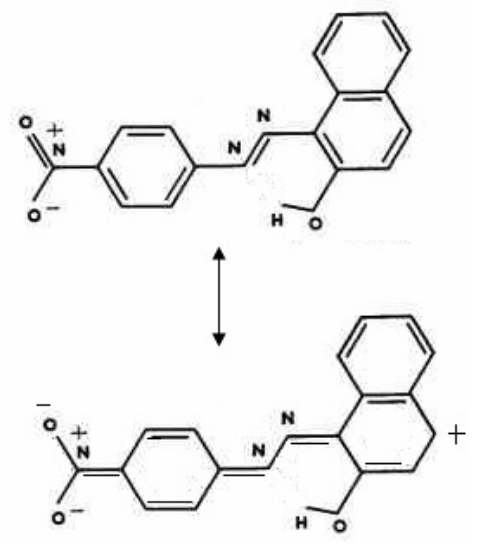

Figure 6. Represent the hyperconjugation system of para red molecule.

The biological activity against two types of both gram positive and gram negative microorganism were studied. Azo dye sulfonamide is totally inactive in vitro but possesses excellent activity in vivo. Trefouel et al. ${ }^{9}$ performed a structure-activity study on the sulfonamide azo dyes and concluded that the azo linkage was reductively cleaved to release the active antibacterial, nocardia, chlamydia trachomatis and some protozoa. Some enteric bacteria are inhibited some of sulfonamides are drugs of choice for infections such as $\mathrm{P}(\mathrm{P})$ toxoplosmosis, nocardiosis and other bacterial infections. The mechanism of action of sulfonamide is competitively inhibit the action of dihydropteroate synthase and blocking the net biosynthesis of folate coenzymes, therefore its bacteriostatic ${ }^{10}$.

\section{Conclusion}

The studies confirm para red was prepared from react diazonium salt of $p$-nitroanilin with $\beta$ naphthol. The derivatives of para red were prepared. The products; dye I, dye II and dye III were characterized by FTIR and UV-Visible spectrophotometer. The antibacterial activity was studied of azo dyes. The in vitro study was shows there is no biological activity of azo dyes.

\section{References}

1. Heinrich Z, Color Chemistry, Syntheses, properties and applications of organic dyes and pigments, VCH, 1991, 496.

2. David L, Review of Progress in Coloration and Related Topics, 1999, 29, 23-28.

3. Stolz A, Springer Verlage, 2001, 56(2), 69.

4. Paraneswari N, Muthakrishnan J and Guanasekaran P, Indian J Exp Biol., 2006, 44, 618.

5. Brown D and Laboureur P, Chemosphere, 1983, 12(3), 405.

6. Wilson and Gisvold's, Text book of organic medicinal and pharmaceutical chemistry, $11^{\text {th }}$ Ed., Lippincott, USA, 2004, 269.

7. Kucharski S and Janik R, New J Chem., 1999, 23, 765.

8. Silverstein R M and Webster F X, Spectrometric Identification of Organic Compounds, $6^{\text {th }}$ Ed. John Wiley \& Sons, Inc., 1999.

9. Trefouel J, Nitti F and Bovet D, C R Seances Soc Biol.,1935, 120, 756.

10. Anand N, Sulfon amides and sulfones, In Wollf M E (Ed.) Burger's, Medicinal Chemistry, Vol.2, $5^{\text {th }}$ Ed ,Wiley, NY, 1996, Chap 33. 


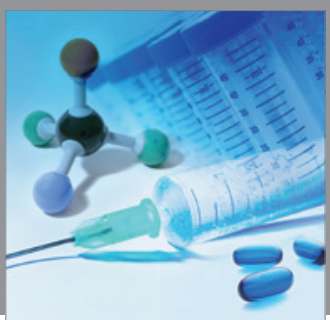

International Journal of

Medicinal Chemistry

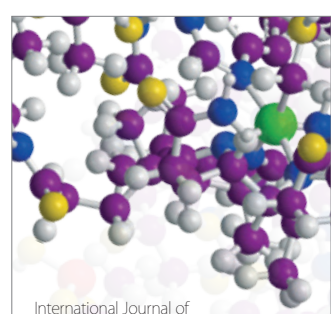

Carbohydrate Chemistry

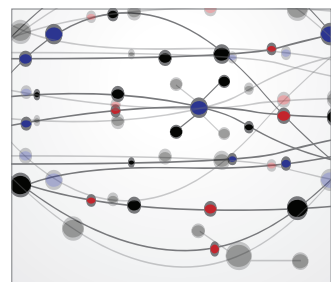

The Scientific World Journal
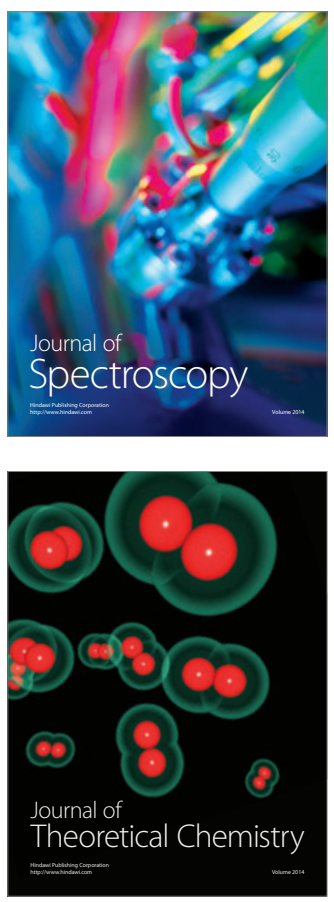
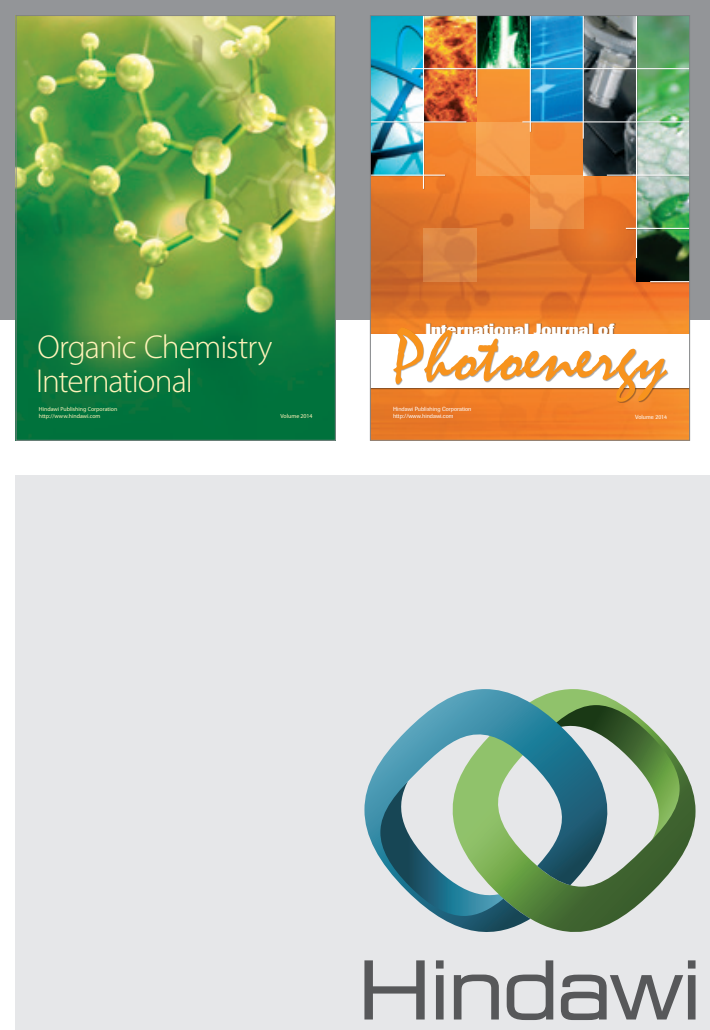

Submit your manuscripts at

http://www.hindawi.com
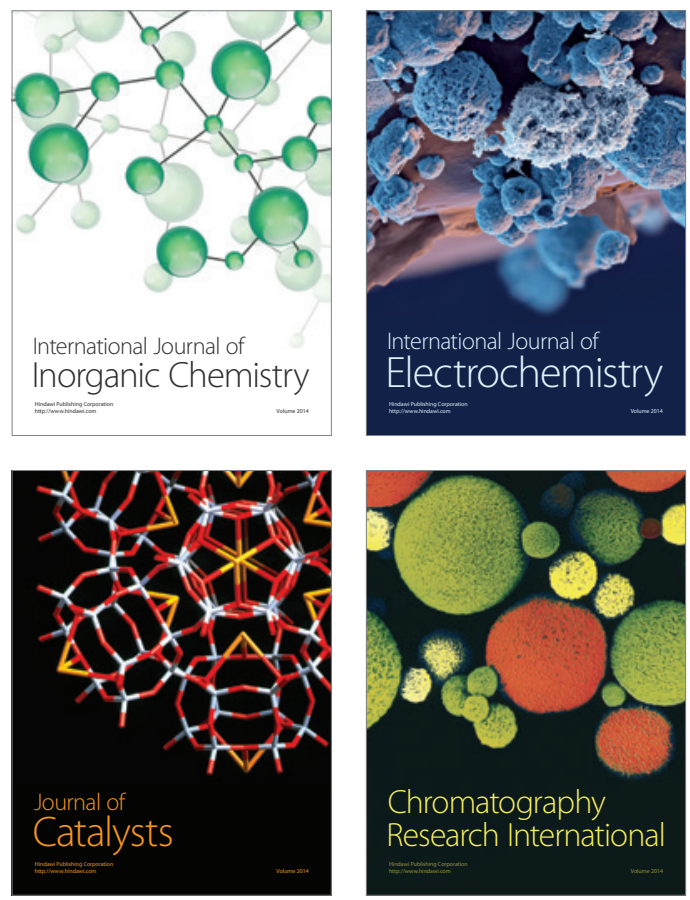
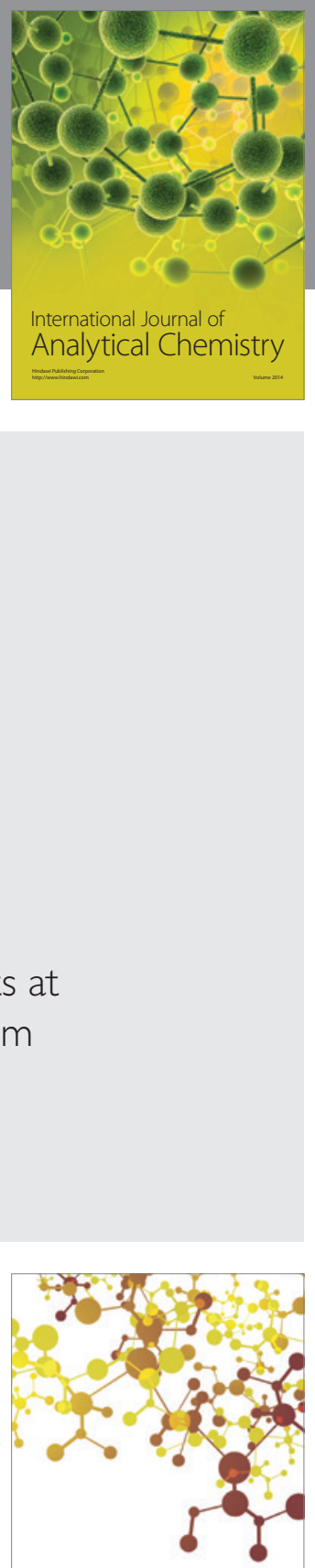

Journal of

Applied Chemistry
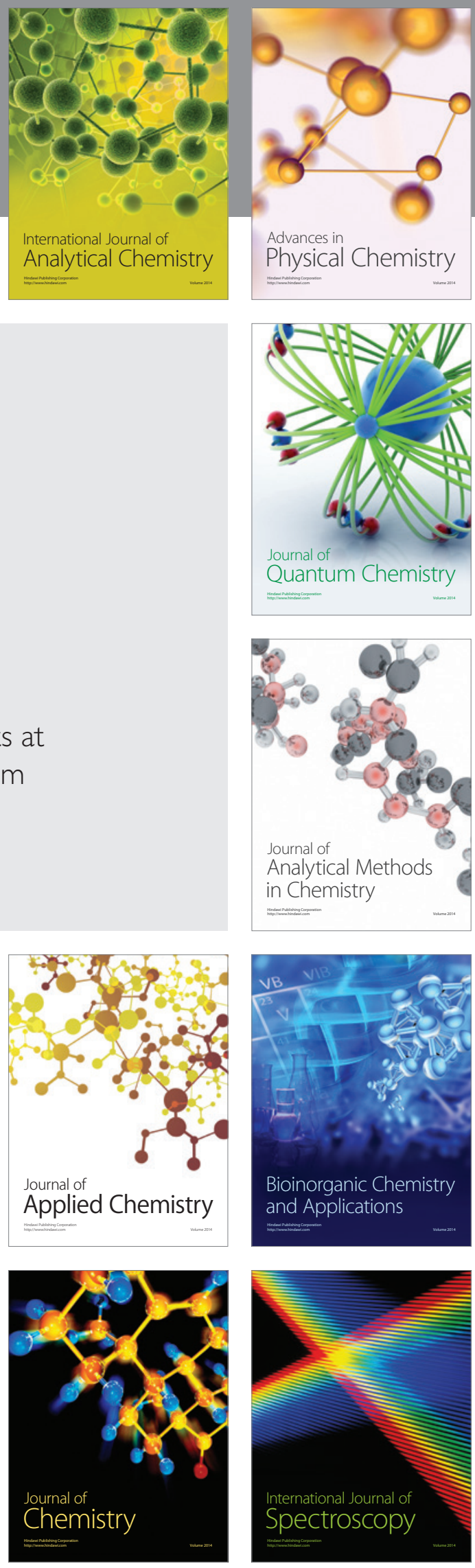